rejection. In the University of Minnesota several patients have received pancreatic transplants from living related donors. ${ }^{12}$ In some cases the donor has given both the kidney and the pancreas. Removal of the hemipancreas is a more formidable operation than nephrectomy and the danger to the donor, not only from surgical complications but also from the possibility that the donor might develop diabetes, is a serious consideration that has deterred most other centres from this approach.

In two patients under the care of Sutherland et al in Minnesota islet cell function stopped abruptly in grafts that came from living donors (personal communication), in one case a sibling and the other an identical twin. In the former the histological appearances of the pancreas were normal apart from the absence of $\beta$ cells in the islets. In the latter there was intense mononuclear cellular infiltration confined to the islet tissue. Though conclusions on these observations must be tentative, these may be examples of the patient's own autoimmune disease that caused the diabetes affecting the grafted islets. Possibly this mechanism may have been responsible for the failure of other allografts but was not recognised as such owing to superimposed rejection. Appropriate immunosuppression might control autoimmune isletitis, and there are early pointers in this direction in patients with juvenile onset diabetes treated with cyclosporin A by Stiller and colleagues in London, Ontario. ${ }^{13}$

Despite flurries of optimism, the results of grafting of the pancreas still lag a long way behind those of kidney grafting. Even if this gap were abolished, moreover, there would be serious difficulties in obtaining enough pancreases for the very many patients afflicted with disabling progressive microangiopathy.

R Y CALNE

Professor of Surgery,

University of Cambridge,

Cambridge CB2 2QQ

${ }^{1}$ Gray BN, Watkins E Jr. Prevention of vascular complications of diabetes by pancreatic islet transplantation. Arch Surg 1976;111:254-7.

${ }^{2}$ Mandel TE, Georgiou H, Hoffman L, Carter WM, Koulmanda M, Dennington P. Proliferation of cultured and isografted fetal mouse pancreatic islets. Transplant Proc 1983;15:1362-5.

${ }^{3}$ Calne RY, Rolles $\mathrm{K}$, White DJG, et al. Cyclosporin $\mathrm{A}$ initially as the only immunosuppressant in 34 recipients of cadaveric organs: 32 kidneys, 2 pancreases, and 2 livers. Lancet 1979 ;ii :1033-6.

${ }^{4}$ Lillehei RC, Simmons RL, Najarian JS, et al. Pancreatico-duodenal allotransplantation: experimental and clinical experience. Ann Surg 1970;172:405-36.

${ }^{5}$ Gliedman ML, Gold M, Whittaker J, et al. Clinical segmental pancreatic transplantation with ureter-pancreatic duct anastomosis for exocrine drainage. Surgery 1970;74:171-80.

${ }^{6}$ Dubernard $M$, Traeger J, Neyra $P$, Touraine JL, Tranchant $D$, BlancBrunat N. A new method of preparation of segmental pancreatic grafts for transplantation: trials in dogs and in man. Surgery 1978; 84:633-9.

'Sutherland DER. Current status of pancreas transplantation: registry statistics and overview. Transplant Proc 1983;15:1303-7.

${ }^{8}$ Calne RY, McMaster P, Rolles K, Duffy TJ. Technical observations in segmental pancreas allografting: ubservations on pancreatic blood flow. Transplant Proc 1980;13, suppl 2:51-7.

${ }^{9}$ Calne RY, White DJG, Rolles K, Duffy TJ, Kass T. Renal and segmental pancreatic grafting with draining of exocrine secretion and initial continuous intravenous cyclosporin $\mathrm{A}$ in a patient with insulindependent diabetes and renal failure. $\mathrm{Br}$ Med $\mathcal{f} 1982 ; 285: 677-80$.

${ }^{10}$ Groth CG, Collste H, Lundgren G, et al. Successful outcome of segmental human pancreatic transplantation with enteric exocrine diversion after modifications in technique. Lancet 1982 ;ii :522-4.

${ }^{11}$ Groth CG, Lundgren G, Gunnarsson R, Härdstedt C, Östman J. Segmental pancreatic transplantation with special reference to the use of ileal exocrine diversion and to the hemodynamics of the graft. Transplant Proc 1980;12, suppl 2:62-7.

${ }^{12}$ Sutherland DER, Goetz FC, Elick BA, Najarian JS. Experience with 49 segmental pancreas transplants in 45 diabetic patients. Transplantation $1982 ; 34: 330-8$.

${ }^{13}$ Stiller CR, Laupacis A, Dupre J, et al. Cyclosporine for treatment of early type I diabetes: preliminary results. $N$ Engl f $\mathrm{Med} 1983 ; 308$ : 1226-7.

\section{Dementia: biological solution still a long way off}

The year 2000 will see a considerable demographic shift in the age structure of the world's population. In 1970 there were 291 million people over the age of 60 and, of these, 26 million were over 80 . The corresponding figures for the end of the century are expected to be in the region of $600 \mathrm{mil}-$ lion and 58 million respectively-with $20 \%$ or more of the over 80 s being demented. Of those affected at present, $55 \%$ suffer from senile dementia of Alzheimer type and 15\% from multi-infarct dementia. Some $22 \%$ suffer from mixed forms of dementia, and the remainder from various other, less common but nevertheless important and in some cases potentially reversible conditions. ${ }^{1}$

The demographic change will occur over a fairly short period, and adaptation is difficult in the face of rapid change. The need for increased residential accommodation will continue to grow, not only because of the continuing expansion in the numbers of over 80 s, the main recipients of such care, but also because of the increased survival of those in institutions. ${ }^{2}$ Bergman and colleagues have shown that intense community care in the form of day hospitals will not dispense with the need for beds. ${ }^{3}$ The problems will be further exacerbated by the changing expectations of the "young" elderly and their attendant relatives after many years' experience of Health Service care.

The main focus of the conference on research progress in dementia held at the Charing Cross Hospital Medical School in London in July was concerned with senile dementia of Alzheimer type. Its clinical features include the slow development of failure of memory and intellect, loss of interest, aimlessness, blunted emotion, and lack of insight. The condition often starts with depression and is accompanied by wide ranging cognitive deficits, which include dysphasia, dyscalculia, visuospatial defects, and difficulties in abstract thinking and orientation. This widespread disorder of cortical functioning is reflected in the pathological changes with lesions not only in the cerebral cortical tissue but also in the subcortical nuclei whose cell bodies have axonal projections to the cortex.

Interest in the neurological aspects of senile dementia of Alzheimer type began with research implicating the cholinergic system, ${ }^{4}$ whose neurones arise in the basal nucleus. Marker enzymes of this system, choline acetyltransferase and acetylcholinesterase, were shown to have reduced activity, the extent correlating well with the severity of the dementia. Furthermore, the neuronal content of these nuclei was shown to be reduced and neurofibrillary tangles were identified. Since then other subcortical nuclei and their transmitter systems have been brought into the picture, including the locus ceruleus, which is noradrenergic; the raphe nucleus, which is serotoninergic; and the substantia nigra, which is dopaminergic. The precise relation of changes in some of these systems to senile dementia of Alzheimer type still remains uncertain, however, since these nuclei play some part in the process of aging in patients who do not show evidence of dementia. Nevertheless, in addition to the cholinergic system the noradrenergic system seems likely to be implicated: indices of malfunctioning in this system correlate with the degree of dementia and with pathological indices of dementia such as the senile plaque count.

Why these four systems should be affected specifically in senile dementia of Alzheimer type we do not know. They 
certainly have common characteristics, such as large cell bodies, and all are unmyelinated. Furthermore, they all have long but distinctive projection patterns, and these common factors may possibly present a common vulnerability. The neurochemical and neuropathological similarities between patients with Down's syndrome aged over 40 and patients with Alzheimer's disease suggest a possible genetic basis, though no genetic links have been found between these two conditions. Whether the cortical changes are purely a reflection of, or are secondary to, the subcortical changes is unsubstantiated. Certainly there is a reduction in somatostatin, an intracortical transmitter, but this is not specific for senile dementia of Alzheimer type. Studies in animals show that a lesion in the basal nucleus will cause secondary changes in cortical neurones. The acetylcholinesterase activity is reduced in the cortex, and this correlates closely with the size of the lesion, but other transmitter systems such as noradrenaline and 5-hydroxytriptamine are unaffected.

The finding of specific abnormalities in the cholinergic system initially of patients with senile dementia of Alzheimer type held out a promise that a treatment might be found to reverse or halt the progress of the disease. So far, however, short term studies of therapeutic trials of precursors of acetylcholine have been disappointing. Possibly these trials did not follow up patients for long enough to give a definitive answer. Dr R Levy reported preliminary findings of a double blind placebo controlled trial of lecithin administered for six months with assessments after six months and at a year. His tentative findings of improvements in certain cognitive features with continued deterioration in others in the treatment group reflect the complexity implied by the biochemical findings. Furthermore, in such studies the clinician may not be certain that he is dealing with a "pure" group of senile dementia of Alzheimer type.

Distinguishing senile dementia of Alzheimer type from multi-infarct dementia or mixed forms has in the past relied to a large extent on the clinical history-together with physical examination and such rating scales as the Hachinski ischaemic score ${ }^{5}$ a predictive scale based on clinical evidence of ischaemia. Patients with multi-infarct dementia do not show evidence of disruption in any of the transmitter systems that have been found to be affected in senile dementia of Alzheimer type. Imaging procedures may distinguish between the two conditions. Computed tomography shows patients with senile dementia of Alzheimer type to have more appreciable ventricular dilatation than those with multi-infarct dementia; local changes, particularly in the temporal regions, are more frequent in the multi-infarct dementia group. The two conditions can be distinguished by measuring oxygen utilisation in positron emission tomography. Oxygen utilisation is reduced in both conditions, but this is more generalised in senile dementia of Alzheimer type, compared with the patchy change in multi-infarct dementia. These features are more pronounced in the grey matter. In senile dementia of Alzheimer type the reduced utilisation is due to the reduced oxygen requirements of ailing neurones, whereas in multiinfarct dementia relatively healthy neurones are being starved of oxygen by an impoverished blood supply. More recently nuclear magnetic resonance imaging has entered the arena. This technique uses the behaviour of protons subjected to the influence of a magnetic field. Images of the brain may be constructed with the proton density (a measure of the proton concentration in free water and lipids in the tissue) and the spin lattice relaxation time (a measure of the degree of freedom of these protons). Measurements of these two features in the white matter have shown that they change differently in patients with senile dementia of Alzheimer type and multiinfarct dementia, and the non-demented elderly and are present even in the absence of identifiable visual lesions. The spin lattice relaxation time also correlates with the severity of the dementia. The ability to make a more definitive diagnosis during life will be helpful in the evaluation of patients for future therapeutic trials.

Nevertheless, a biological solution to dementia is still a long way off. In the search for it we should not lose sight of the large and growing numbers of demented elderly who will not benefit. The current pressing needs remain those of providing and evaluating adequate services for such demented patients and their families. In the words of Jolly and Arie: "the care of the elderly with mental disorders is likely to be the biggest challenge to health services in all countries such as ours for the foreseeable future."'

JOHN BESSON

Senior Lecturer in Mental Health supported by the

Wellcome Foundation,

University of Aberdeen,

Royal Cornhill Hospital,

Aberdeen AB9 2ZH

1 Tomlinson BE, Blessed G, Roth $M$. Observations on the brains of demented old people. $\mathcal{F}$ Neurol Sci 1970;11:205-42.

${ }^{2}$ Christie AB. Changing patterns in mental illness in the elderly. $B r f$ Psychiatry 1982;140:154-9.

${ }^{3}$ Bergman K, Foster EM, Justice AW, Matthews V. Management of the demented elderly patient in the community. Br $\mathcal{F}$ Psychiatry 1978; $132: 441-9$.

${ }^{4}$ Davies P, Maloney AJF. Selective loss of central cholinergic neurons in Alzheimer's disease. Lancet 1976;ii:1403.

${ }^{5}$ Hachinski VC, Iliff LD, Zilhka E, et al. Cerebral blood flow in dementia. Arch Neurol 1975;32:632-7.

6 Jolley DJ, Arie T. Organization of psychogeriatric services. Br F Psychiatry 1978;132:1-11.

\section{$Q$ fever}

In 1937 Derrick described the clinical features of an acute undiagnosed illness which was prevalent among abattoir workers in Brisbane. ${ }^{1} \mathrm{He}$ called the illness " $Q$ fever," the $Q$ (query) referring to the unknown cause of the disease. The aetiology of the infection was eventually established when Burnet cultured a micro-organism from the blood of an affected patient. This rickettsia like organism was originally called Rickettsia burnetii, but was later renamed Coxiella burnetii when Cox found that it had certain features which differentiated it from the true rickettsiae.

$C$ burnetii is carried by many insects, ticks, and animals. The principal reservoir of human infection in Britain is probably cattle and sheep, in which infection is usually subclinical. The exact method of transmission of the organism to man is uncertain. Airborne spread is considered to be an important route and unpasteurised milk is another. Of 16 patients diagnosed as having chronic or fatal $\mathrm{Q}$ fever in north east Scotland between 1967 and $1980,{ }^{2} 10$ had had close contact with farms, farm products, or farm animals, and unpasteurised milk was considered to be a possible source of infection in several of these patients. Although it is important to consider $Q$ fever in patients living in rural areas who present with undiagnosed febrile illness or with evidence of endocarditis, it is also important to remember that the disease may occur in patients in 